\title{
Dose-response relationship of inhaled budesonide in adult asthma: a meta-analysis
}

\author{
M. Masoli*, S. Holt" ${ }^{\#}$ M. Weatherall ${ }^{\top}$, R. Beasley*,+
}

Dose-response relationship of inhaled budesonide in adult asthma: a meta-analysis. M. Masoli, S. Holt, M. Weatherall, R. Beasley. (C) ERS Journals Ltd 2004.

ABSTRACT: The aim of this study was to examine the dose-response relationship of inhaled budesonide in adolescents and adults with asthma.

A meta-analysis was carried out on placebo-controlled, randomised clinical trials, presenting data on at least one outcome measure of asthma and using at least two doses of budesonide, delivered by turbuhaler or metered-dose inhaler+spacer twice daily.

A total of six studies of 1,435 adolescents and adults, with mild to moderately severe asthma, met the inclusion criteria for the meta-analysis. A negative exponential model indicated that $80 \%$ of the benefit at $1,600 \mu \mathrm{g} \cdot \mathrm{day}^{-1}$ was achieved at doses of $\sim 200-400 \mu \mathrm{g} \cdot \mathrm{day}^{-1}$ and $90 \%$ by $300-600 \mu \mathrm{g} \cdot \mathrm{day}^{-1}$. Meta-regression with a quadratic term in dose showed that the maximum effect was obtained with doses of $\sim 1,000 \mu \mathrm{g} \cdot \mathrm{day}^{-1}$.

In conclusion, the available published data indicate that, in adolescents and adults with mild to moderate asthma, most of the therapeutic benefit of budesonide delivered by turbuhaler or metered-dose inhaler + spacer is achieved with a dose of $\sim 400 \mu \mathrm{g} \cdot \mathrm{day}^{-1}$ and the maximum effect is achieved at $\sim 1,000 \mu \mathrm{g} \cdot \mathrm{day}^{-1}$. This conclusion is qualified by the recognition that there is considerable individual variability in the response to inhaled corticosteroids and that the subjects included in this meta-analysis had predominantly mild to moderate asthma.

Eur Respir J 2004; 23: 552-558.
*Medical Research Institute of New Zealand, ${ }^{\#}$ P3 Research, and "Wellington School of Medicine \& Health Sciences, Wellington, New Zealand. ${ }^{+}$University of Southampton, Southampton, UK.

Correspondence: R. Beasley

Medical Research Institute of New Zealand PO Box 10055

Wellington

New Zealand

Fax: 6444729224

E-mail: richard.beasley@mrinz.ac.nz

Keywords: Adults

asthma

budesonide

dose-response

inhaled corticosteroids

meta-analysis

Received: July 32003

Accepted after revision: December 152003
In a recent meta-analysis of the dose-response relationship of fluticasone, it was shown that most of the therapeutic benefit is achieved with doses of 100-250 $\mu \mathrm{g} \cdot \mathrm{day}^{-1}$, and that the maximum effect is obtained at $\sim 500 \mu \mathrm{g} \cdot$ day $^{-1}$ in adolescents and adults with asthma [1]. This therapeutic dose range is two-fold lower than that recommended in the international and national consensus guidelines and formularies, and the dose commonly prescribed in clinical practice [2-4]. In view of this disparity and in response to the recommendations of the Cochrane Centre [5], the current authors have further investigated the therapeutic dose range of inhaled corticosteroids by undertaking a similar meta-analysis of the doseresponse relationship of budesonide.

\section{Methods}

A search of Medline was conducted from Jan 1966 to Jan 2003 and of Embase from Jan 1980 to Jan 2003. On Medline, studies were searched using a combination of the keywords "budesonide" and "dose" or "dosage". AstraZeneca, the manufacturer of budesonide, was also asked for details of all relevant studies; no additional studies were identified. No relevant studies published in other languages were found on Medline or Embase. Finally, the reference lists of relevant studies were examined and no other studies were found.

\section{Inclusion criteria}

Two people examined each paper's title and abstract, and then the full paper if necessary. To be included in the primary meta-analysis, studies had to meet all of the following criteria: a double-blind, placebo-controlled, randomised trial involving two or more doses of budesonide, delivered by turbuhaler or metered-dose inhaler (MDI)+spacer device twice daily, in adolescents (aged $>12$ yrs) or adults with asthma, of at least 4 weeks in duration. The decision to include studies using the turbuhaler and MDI+spacer was based on evidence that both delivery systems achieved similar lung deposition, greater than that with the MDI alone [6, 7], although it is noted that a formal dose-response comparison between the two devices was not undertaken. The search strategy recommended by the QUORUM statement is shown in figure 1. Letters were sent to the authors of three out of six studies included in the metaanalysis to obtain the data in the format required.

\section{Data extraction}

Extraction of data was based on reported summary statistics (mean, SD, SEM) for the intention-to-treat population. The outcome measures assessed were forced expiratory volume in one second (FEV1) measured at the clinic, peak expiratory flow (PEF; both morning and evening), use of $\beta$-agonists, total withdrawals and exacerbations of asthma leading to withdrawal.

\section{Data analysis}

For each outcome measure, the mean change reported in each study was plotted against the total daily dose of 


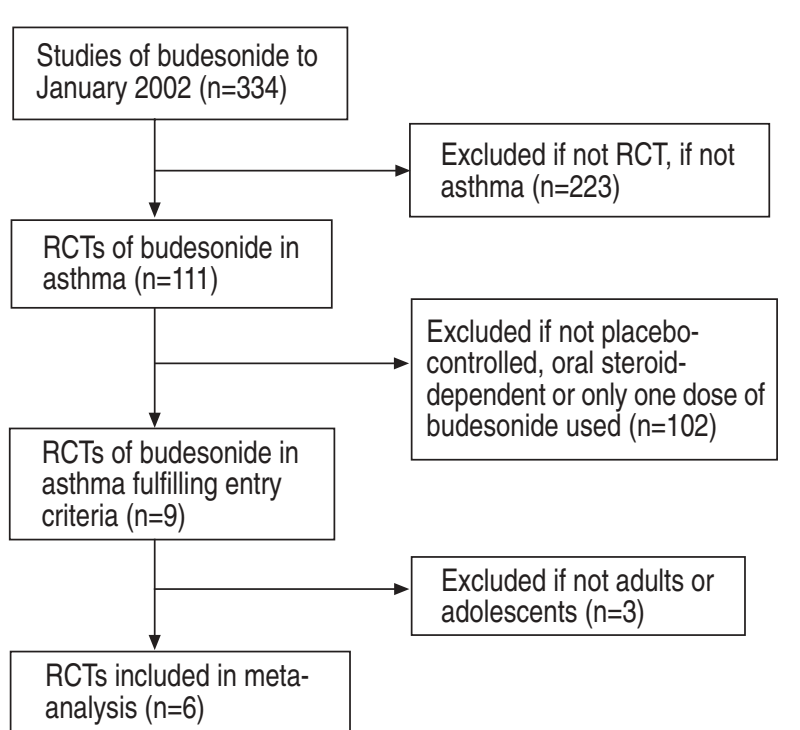

Fig. 1.-Process of inclusion of studies in the meta-analysis. RCT: randomised controlled trial.

budesonide. A negative exponential curve of the mean relative percentage change from baseline for each outcome measure was modelled, weighted by the number of participants in the study. From this graph, the doses at which 80 and $90 \%$ of the effect obtained with $1,600 \mu \mathrm{g} \cdot \mathrm{day}^{-1}$ were determined. The effect obtained with $1,600 \mu \mathrm{g} \cdot$ day $^{-1}$ was considered to be the "maximum effect" for the purposes of this analysis. The confidence intervals of the outcome measures of this model could not be estimated from the published data.

Meta-regression was used to compare the effect of change in dose of budesonide on the asthma response variables. A general linear model, weighted by the inverse of the calculated variance for each variable, was used $[8,9]$. Scatter plots of the response and explanatory variable (the total daily dose of inhaled budesonide) suggested a curved relationship, therefore, a quadratic model was used for this measure. The variance for each response variable was calculated from the SD or SE cited in the extra data from the authors, by using the initial number of patients for each treatment category. Analysis of residuals indicated that normality and other assumptions were met. The peak dose effect for the quadratic model was calculated by the following equation:

$$
\beta_{1} /\left(2 \times \beta_{2}\right)
$$

where $\beta 1$ is the parameter for the dose of budesonide and $\beta 2$ the parameter for the square of the dose. The weighted model variance was used to calculate $95 \%$ confidence intervals (CI) for the predicted peak dose. Both fixed-effects and randomeffects models were used.

A meta-analysis was undertaken to establish the difference in effect on FEV1 and PEF of an inhaled dose of $400 \mu \mathrm{g} \cdot \mathrm{day}^{-1}$ budesonide, as compared with higher doses, based on the standardised difference in FEV1 and PEF for the studies in which these data were available [10]. The standardised difference represented the differences in the means, divided by the pooled within-groups SD. Both fixed- and random-effects models were fitted.

Due to heterogeneity between studies and the low numbers involved, it was not possible to perform a meaningful statistical analysis of the data for withdrawals due to exacerbations of asthma. Likewise, the relatively high frequency of withdrawals due to events other than an exacerbation of asthma in two of the four studies that reported these data also meant that the total withdrawal data could not be analysed.

\section{Results}

\section{Description of the studies}

Six studies met the criteria for inclusion in this analysis [11-16]. These studies were published between 1990 and 2000 and were of 4-16 weeks in duration (table 1). A total of 1,435 adolescents and adults with asthma were included in the studies, with a mean age (range) of 41 yrs (12-70). In most studies, the patients had mild to moderately severe asthma, with a mean FEV1 of $69 \%$ pred at enrolment. The doses of budesonide ranged $200-1,600 \mu \mathrm{g} \cdot \mathrm{day}^{-1}$; only one study used a dose of budesonide $>800 \mu \mathrm{g} \cdot$ day $^{-1}$. The funnel plots (data not shown) did not suggest publication bias, although it is acknowledged that with only six studies, this provides only limited support.

\section{Plots of mean change in outcome measures at different doses}

Plotting the raw data for each outcome measure against the dose of budesonide showed most of the benefit was achieved at a dose of $200-500 \mu \mathrm{g} \cdot \mathrm{day}^{-1}$, with little further improvement at higher doses.

Determination of the dose at which 80 and $90 \%$ of the effect obtained with 1,600 $\mu \mathrm{g} \cdot d a y^{-1}$ is achieved

From the negative exponential line of best-fit derived from the weighted means of the effect at each dose, it was calculated that $80 \%$ of the benefit obtained with $1,600 \mu \mathrm{g} \cdot \mathrm{day}^{-1}$ was achieved at doses of $200-400 \mu \mathrm{g} \cdot \mathrm{day}^{-1}$ and $90 \%$ at doses of $300-600 \mu \mathrm{g} \cdot \mathrm{day}^{-1}$, depending on the outcome measure (table 2). The plot of the per cent predicted maximum effect based on the negative exponential model for all four major clinical outcome measures is shown in figure 2 .

\section{Determination of the dose at which the maximum response is achieved}

The dose of the peak effect ranged $881-1,090 \mu \mathrm{g} \cdot \mathrm{day}^{-1}$ for the different outcome variables (table 3 ). The maximum increase in FEV1 was $0.32 \mathrm{~L}$, utilising the fixed-effects model.

Effect on FEV1 of a dose of $400 \mu \mathrm{g} \cdot \mathrm{day}^{-1}$ budesonide, as compared with higher doses

The meta-analysis of the standardised difference in FEV1 at a dose of $400 \mu \mathrm{g} \cdot \mathrm{day}^{-1}$ compared with higher doses showed a difference in FEV1 of $0.05 \mathrm{SD}$, with a CI that included zero $(-0.12-0.22)$. The pooled SDs for the three studies reporting FEV1 ranged -0.083-0.1141. The homogeneity statistic was not significant. Forest plots of FEV1 did not suggest that a dose of $400 \mu \mathrm{g} \cdot \mathrm{day}^{-1}$ produced an inferior response as compared to $\geqslant 800 \mu \mathrm{g} \cdot \mathrm{day}^{-1}$ (fig. 3).

Effect on peak expiratory flow of a dose of $400 \mu \mathrm{g} \cdot \mathrm{day}^{-1}$ budesonide, as compared with higher doses

The meta-analysis of the standardised difference in PEF at a dose of $400 \mu \mathrm{g} \cdot \mathrm{day}^{-1}$ as compared with higher doses showed a difference in PEF of $3.7 \mathrm{~L} \cdot \mathrm{min}^{-1}(-5.8-13.2)$. Forest plots of 


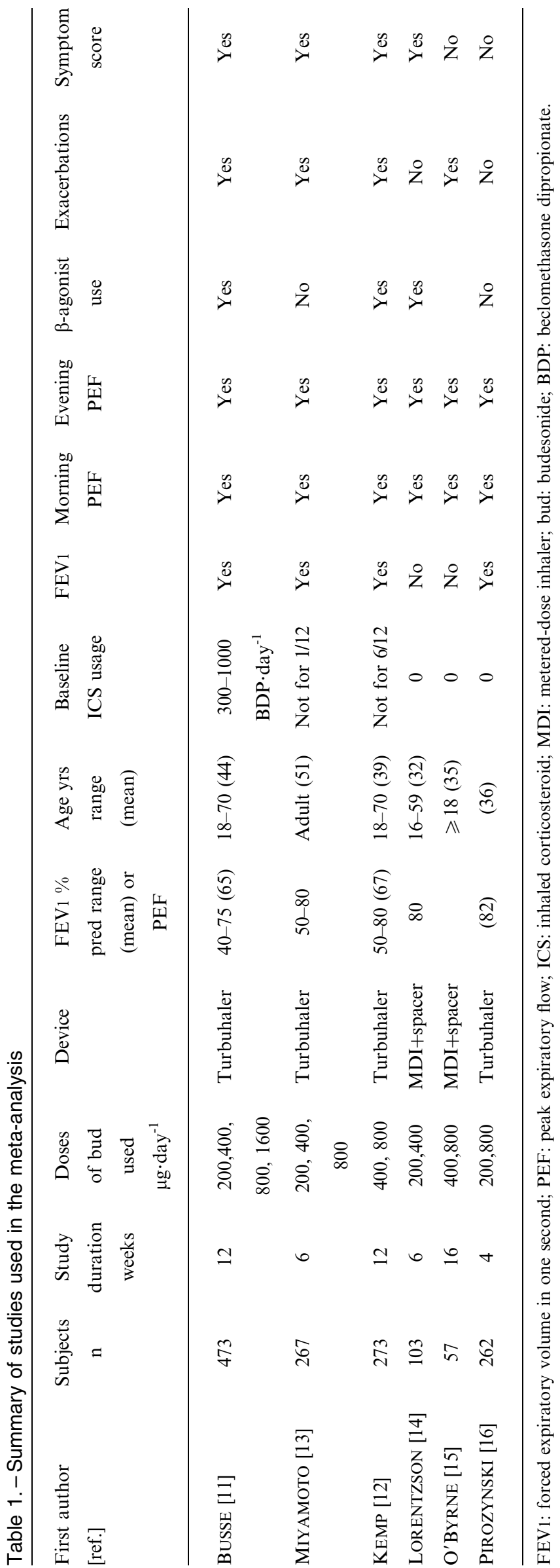

Table 2. - Doses of budesonide $\left(\mu \mathrm{g} \cdot \mathrm{day}^{-1}\right)$ at which 80 and $90 \%$ of the maximum effect is achieved, as derived from a negative exponential model

\begin{tabular}{lcc}
\hline Outcome measure & $\begin{array}{c}80 \% \text { of max. } \\
\text { effect achieved }\end{array}$ & $\begin{array}{c}90 \% \text { of max. } \\
\text { effect achieved }\end{array}$ \\
\hline FEV1 & 315 & 450 \\
Morning PEF & 230 & 329 \\
Evening PEF & 412 & 589 \\
$\beta$-agonist use & 204 & 293 \\
\hline
\end{tabular}

The effect obtained with $1600 \mu \mathrm{g} \cdot \mathrm{day}^{-1}$ budesonide was considered to be the "maximum effect" for the purposes of this analysis. FEV1: forced expiratory volume in one second; PEF: peak expiratory flow.

PEF did not suggest that a dose of $400 \mu \mathrm{g} \cdot \mathrm{day}^{-1}$ gave an inferior response as compared to $\geqslant 800 \mu \mathrm{g} \cdot \mathrm{day}^{-1}$ (fig. 4).

\section{Withdrawals due to asthma}

The data for total withdrawals or for exacerbations of asthma leading to withdrawal could not be analysed, due to heterogeneity between studies, zero cell counts in different dose groups and the relatively high frequency of withdrawals due to events other than exacerbations of asthma (table 4). Examination of the individual study data indicate that most of the benefit with respect to the reduction in asthma exacerbations leading to withdrawal was achieved with a dose of $400 \mu \mathrm{g} \cdot \mathrm{day}^{-1}$.

\section{Discussion}

This meta-analysis has shown that, in adolescents and adults with mild to moderate asthma, most of the therapeutic benefit of budesonide is achieved with a total daily dose of $\sim 400 \mu \mathrm{g}$ and that the maximum achievable benefit occurs with a dose of $\sim 1,000 \mu \mathrm{g}$. Given that in vitro and clinical studies have indicated a $2: 1$ potency ratio of fluticasone to budesonide and beclomethasone dipropionate (BDP) [17-19], these findings are strongly consistent with the previous fluticasone meta-analysis, which showed that $90 \%$ of clinical benefit was achieved with doses in the range of $150-250 \mu \mathrm{g}$. day $^{-1}$ and the peak effect with a dose of $\sim 500 \mu \mathrm{g} \cdot$ day $^{-1}$ [1]. These findings are also consistent with the recent large doseresponse study of BDP administered via MDI, which reported that the top of the dose-response curve in terms of efficacy was between $400-800 \mu \mathrm{g} \cdot \mathrm{day}^{-1}$, depending on the outcome measure examined [20]. Together, these findings allow determination of the therapeutic dose-response relationship of the different inhaled corticosteroids used in clinical practice, depending on their relative potencies.

\section{Limitations of the study}

The major limitation of this meta-analysis was the paucity of studies using high doses of budesonide; only one study examined a dose $>800 \mu \mathrm{g} \cdot \mathrm{day}^{-1}$. Consequently, one of the findings is that data in the published literature on which to confidently determine the dose relationship of budesonide at high doses is limited. The authors are confident that all available studies were included in the analysis because of the comprehensive search that was undertaken.

The authors were concerned that the requirement for the studies to be placebo-controlled may have led to the exclusion of a number of large dose-response studies examining doses of 

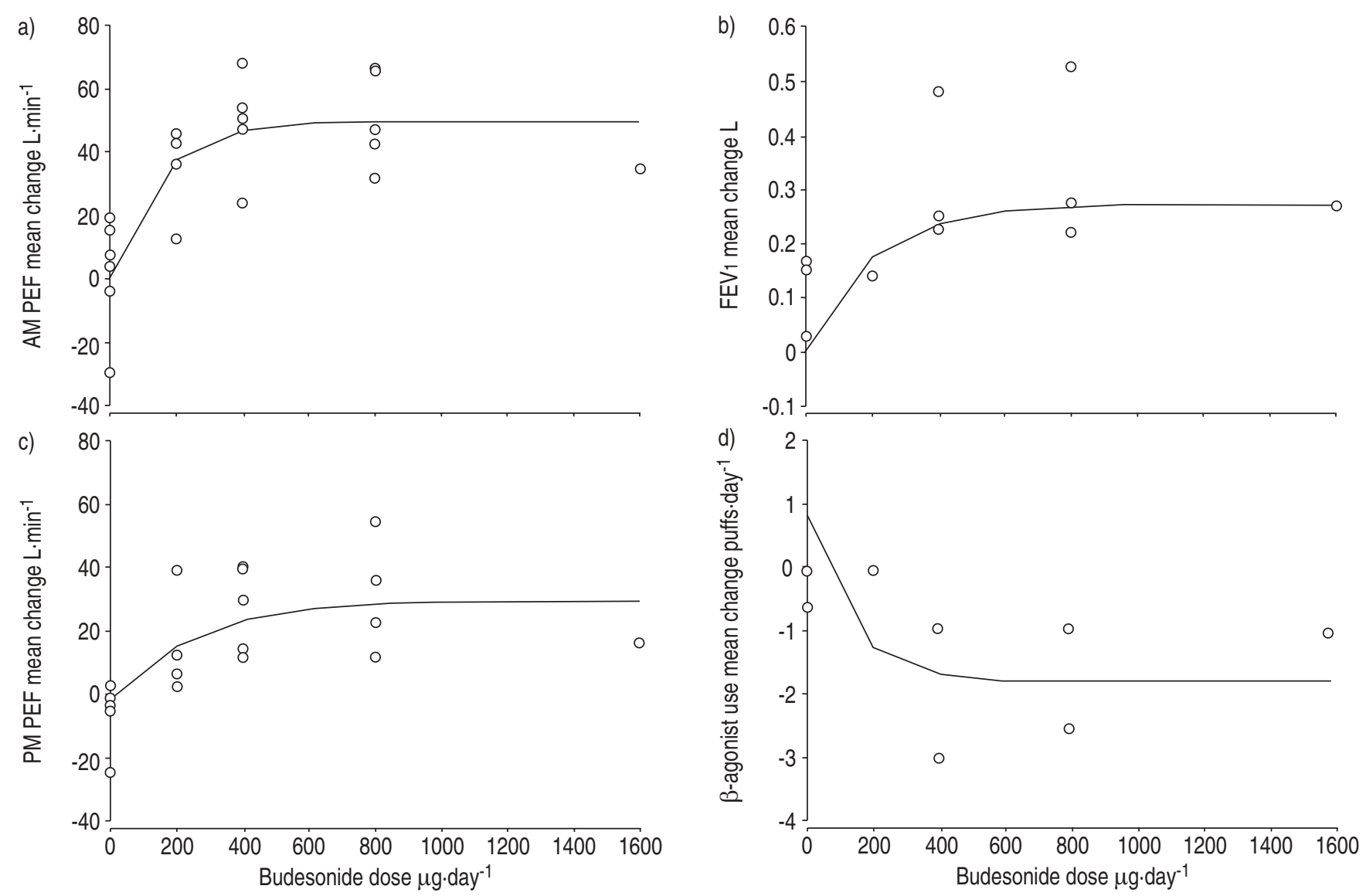

Fig. 2. - Dose-response curve of inhaled budesonide in adult asthma, based on negative exponential model for four clinical outcome measures: a) morning peak expiratory flow (PEF), b) evening PEF, c) forced expiratory volume in one second (FEV1), and d) $\beta$-agonist use

budesonide $>800 \mu \mathrm{g} \cdot \mathrm{day}^{-1}$ and that their inclusion would have enabled the dose-response to be determined at the higher level. However, this was not the case, as only two nonplacebo-controlled studies identified examined doses of $>800 \mu \mathrm{g} \cdot \mathrm{day}^{-1}[21,22]$ and these studies indicated that there was a minimal additional benefit of using doses up to $3,200 \mu \mathrm{g} \cdot \mathrm{day}^{-1}$.

For reasons stated previously, the authors were unable to undertake a meaningful statistical analysis of withdrawals due to worsening asthma. However, examination of data from individual studies suggested that most of the benefit is achieved with a dose of $400 \mu \mathrm{g} \cdot \mathrm{day}^{-1}$. For example, in the large study of BUSSE et al. [11], budesonide at a dose of $400 \mu \mathrm{g} \cdot \mathrm{day}^{-1}$ led to a reduction in withdrawals from asthma from 57 to $10 \%$, with the $1,600 \mu \mathrm{g} \cdot$ day $^{-1}$ dose causing a minimal further reduction to $7 \%$.
It is also acknowledged that the greater number of withdrawals on placebo may have led to an underestimation of the magnitude of the difference in lung function and symptoms between placebo and budesonide. This consideration did not apply to the comparisons between the 400, 800 and 1,600 $\mu \mathrm{g}$ doses of budesonide, in which the proportion of withdrawals was similar.

Another issue is the intersubject variation in response to inhaled corticosteroid therapy, which is likely to result in a proportion of patients requiring doses higher than the observed mean dose to achieve the maximum effect, just as a proportion may well require lower doses. Regrettably the authors were unable to quantify this variability in response, as AstraZeneca were unable to make the individual patient data available and the interpretation of the study findings is limited in this respect.

Table 3. - Estimates of dose of budesonide $\left(\mu \mathrm{g} \cdot\right.$ day $\left.^{-1}\right)$ giving peak effect and effect on mean change in outcome measure

\begin{tabular}{|c|c|c|c|c|c|}
\hline \multirow[t]{2}{*}{ Outcome measure } & \multirow[t]{2}{*}{$\mathrm{R}^{2} \%$} & \multicolumn{2}{|c|}{ Fixed-effects model } & \multicolumn{2}{|c|}{ Random-effects model } \\
\hline & & $\begin{array}{c}\text { Dose of } \\
\text { peak effect }\end{array}$ & $\begin{array}{l}\text { Mean change } \\
\quad(95 \% \mathrm{CI})\end{array}$ & $\begin{array}{c}\text { Dose of } \\
\text { peak effect }\end{array}$ & $\begin{array}{l}\text { Mean change } \\
\quad(95 \% \mathrm{CI})\end{array}$ \\
\hline FEV1 L & 39 & 1084 & $0.29(0.19-0.40)$ & 1090 & $0.30(0.15-0.45)$ \\
\hline Morning PEF $\mathrm{L} \cdot \mathrm{min}^{-1}$ & 39 & 881 & $58.2(45-72)$ & 976 & $61.8(35.4-88.1)$ \\
\hline Evening PEF $\mathrm{L} \cdot \mathrm{min}^{-1}$ & 50 & 926 & $36.6(25-48.2)$ & 1050 & $40.2(11.7-68.8)$ \\
\hline$\beta$-agonist use puffs $\cdot$ day $^{-1}$ & 52 & 965 & $-2.54(-0.78--4.35)$ & 1038 & $-2.76(-6.33--0.81)$ \\
\hline
\end{tabular}

CI: confidence interval; FEV1: forced expiratory volume in one second; PEF: peak expiratory flow. 


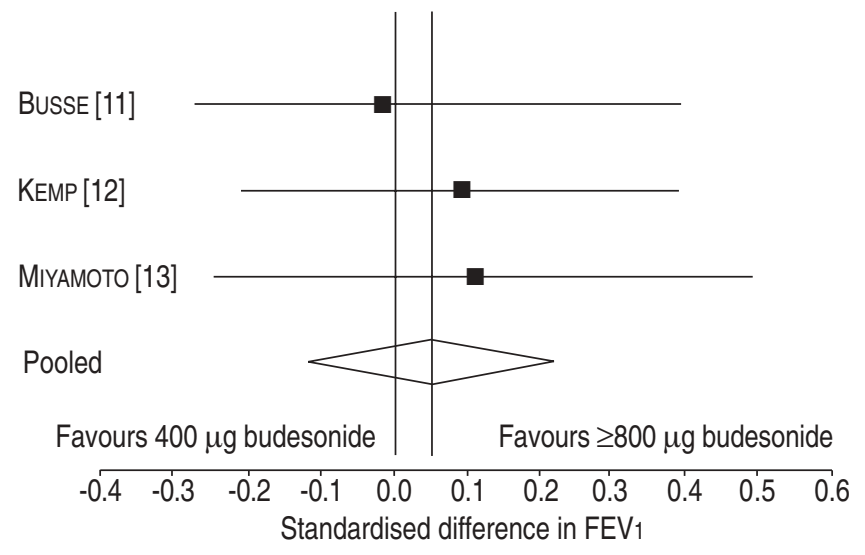

Fig. 3.-Modified Forest plot for standardised difference in forced expiratory volume in one second (FEV 1 ) comparing $400 \mu \mathrm{g} \cdot \mathrm{day}^{-1}$ with doses of $\geqslant 800 \mu \mathrm{g} \cdot \mathrm{day}^{-1}$. Pooled data $=0.05(-0.12-0.22)$.

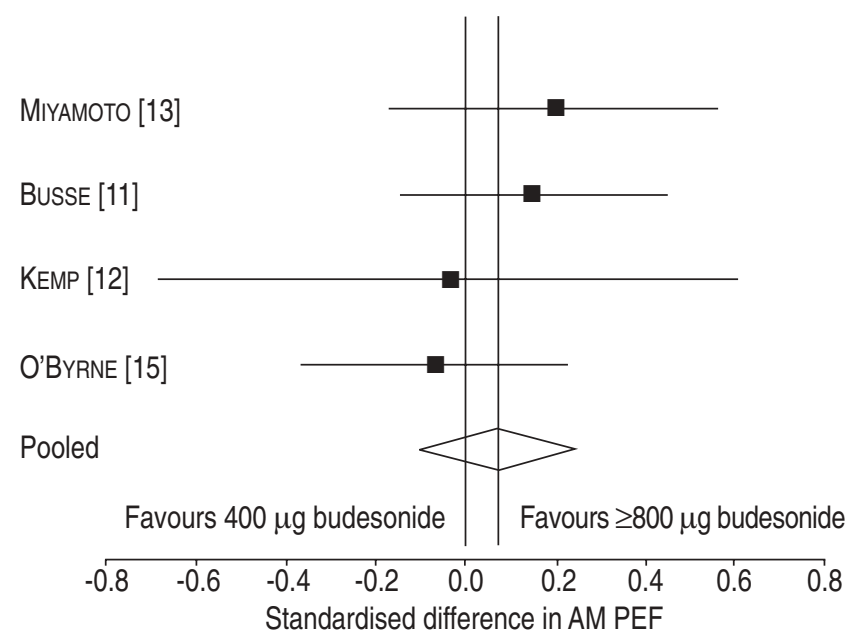

Fig. 4.-Modified Forest plot for standardised difference in morning peak expiratory flow comparing $400 \mu \mathrm{g} \cdot \mathrm{day}^{-1}$ with doses of $\geqslant 800 \mu \mathrm{g} \cdot$ day $^{-1}$. Pooled data $=0.07(-0.11-0.25)$.

\section{Key findings}

There was consistency in the findings from the different methods of analysis; the majority of the clinical effect of inhaled budesonide is achieved at a dose of $250-500 \mu \mathrm{g} \cdot \mathrm{day}^{-1}$, with higher doses providing little further benefit. As with the previous meta-analysis of fluticasone [1], similar dose-response relationships were observed for the different outcome measures, including lung function, symptoms and exacerbations.

The findings are also consistent with other dose-response studies of budesonide that did not include a placebo arm and as a result could not be included in this meta-analysis [21-28]. For example, similar results were found in the studies by CHANEZ et al. [22] and TUKIAINEN et al. [23], which showed no difference between initial treatment with 400 or $1,600 \mu \mathrm{g} \cdot \mathrm{day}^{-1}$ budesonide after 4 weeks, or with 200 or $800 \mu \mathrm{g} \cdot \mathrm{day}^{-1}$ after 12 weeks, respectively. In the FACET study [25], there were clinically significant improvements in asthma control with budesonide taken over a 12-month period at 800 as compared to $200 \mu \mathrm{g} \cdot \mathrm{day}^{-1}$. In contrast, in the 4-week study by VAN DER Molen et al. [28], initial treatment with 200 or $800 \mu \mathrm{g} \cdot \mathrm{day}^{-1}$ budesonide did not result in statistically significant differences for any of the clinical outcome measures. In the only randomised, double-blind study that compared doses of budesonide $>1,600 \mu \mathrm{g} \cdot \mathrm{day}^{-1}$, there was no therapeutic difference between 8 weeks of treatment with 3,200 and $1,600 \mu \mathrm{g} \cdot \mathrm{day}^{-1}$, confirming the lack of further benefit at very high doses [21].

\section{Cases when higher doses may be warranted}

The asthmatic subjects recruited in the studies that were included in the meta-analysis can be considered to have had predominantly mild to moderate asthma, on the basis of a mean FEV1 69\% pred. As a result, although some subjects with severe asthma were included in the studies (lower range in FEV $140 \%$ pred), the findings may not necessarily apply to more severe asthmatics. As has been noted previously, due to individual variability, a proportion of asthmatics may require doses greater than the peak of the dose response observed in this meta-analysis to achieve maximal clinical benefit, just as a proportion may require lower doses.

Furthermore, the current findings do not exclude the

Table 4. - The number of withdrawals and withdrawals due to asthma according to budesonide dose in the three studies

\begin{tabular}{|c|c|c|c|c|}
\hline First author [ref.] & Dose & $\begin{array}{c}\text { Subjects } \\
\mathrm{n}\end{array}$ & $\begin{array}{c}\text { Total withdrawals } \\
\text { n }(\%)\end{array}$ & $\begin{array}{l}\text { Withdrawals due } \\
\text { to asthma n }(\%)\end{array}$ \\
\hline \multirow[t]{5}{*}{ BUSSE [11] } & Placebo & 92 & $55(60)$ & $52(56)$ \\
\hline & $200 \mu \mathrm{g}$ & 91 & $24(26)$ & $16(18)$ \\
\hline & $400 \mu \mathrm{g}$ & 93 & 17 (18) & $10(11)$ \\
\hline & $800 \mu \mathrm{g}$ & 99 & $16(16)$ & $9(9)$ \\
\hline & $1600 \mu \mathrm{g}$ & 98 & $13(13)$ & $7(7)$ \\
\hline \multirow[t]{3}{*}{ KEMP [12] } & Placebo & 89 & $18(20)$ & $14(16)$ \\
\hline & $400 \mu \mathrm{g}$ & 93 & $9(10)$ & $5(5)$ \\
\hline & $800 \mu \mathrm{g}$ & 91 & $5(6)$ & $0(0)$ \\
\hline \multirow[t]{4}{*}{ МіҮАМото [13] } & Placebo & 70 & $18(26)$ & $3(4)$ \\
\hline & $200 \mu \mathrm{g}$ & 63 & $7(11)$ & $0(0)$ \\
\hline & $400 \mu \mathrm{g}$ & 67 & 12 (18) & $1(2)$ \\
\hline & $800 \mu \mathrm{g}$ & 67 & $6(9)$ & $1(2)$ \\
\hline \multirow[t]{3}{*}{ O'BYRNE [15] } & Placebo & 20 & $6(30)$ & $2(10)$ \\
\hline & $400 \mu \mathrm{g}$ & 17 & $4(24)$ & $0(0)$ \\
\hline & $800 \mu \mathrm{g}$ & 20 & $8(40)$ & $0(0)$ \\
\hline
\end{tabular}

\#: the withdrawal data from this study was measured from the graph of discontinuations from the study (fig. 1); this data does not correspond to that

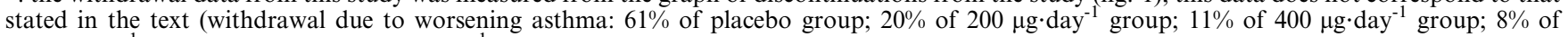
$800 \mu \mathrm{g} \cdot \mathrm{day}^{-1}$ group; and $7 \%$ of $1600 \mu \mathrm{g} \cdot \mathrm{day}^{-1}$ group). 
possibility that there may be certain circumstances when higher doses of budesonide may be useful. There is some evidence that budesonide at $3,200 \mu \mathrm{g} \cdot \mathrm{day}^{-1}$ may be as effective as oral corticosteroid therapy in follow-up treatment after an acute asthma attack [29]. However, a recent meta-analysis by the Cochrane Collaboration suggests that further research is needed to clarify this and that insufficient evidence exists at present for such an inhaled regimen to be implemented [30].

Another clinical situation is the use of high doses of budesonide in oral steroid-dependent asthmatics to enable a reduction in oral steroid dose. Most studies have shown that a significant reduction in oral steroid dose can be achieved with high doses of inhaled corticosteroid therapy, although whether $1,600 \mu \mathrm{g} \cdot \mathrm{day}^{-1}$ of budesonide is superior to $800 \mu \mathrm{g} \cdot \mathrm{day}^{-1}$ is inconclusive [31-33].

\section{Contrasting dose-response relationship of systemic effects}

In contrast to the dose-response with efficacy, adverse systemic effects exhibit a more linear relationship with no evidence of a plateau in response. The two main adverse effects of concern with long-term use of inhaled corticosteroids in adults are adrenal suppression and reduced bone mineral density, with bruising, cataracts and glaucoma also being associated with their use. Studies have shown that doses $>1,000 \mu \mathrm{g} \cdot \mathrm{day}^{-1}$ of budesonide can produce significant suppression of the hypothalamic-pituitary-adrenal axis [34-36]. Indeed, 6 weeks of budesonide treatment at a dose of $3,200 \mu \mathrm{g} \cdot \mathrm{day}^{-1}$ may lead to suppression of adrenal cortisol production of a magnitude similar to that observed with $10 \mathrm{mg}$ of oral prednisone [36].

The cumulative doses of inhaled corticosteroids are particularly important when the adverse effects on bone density are considered in relation to the requirement for lifelong therapy. This is illustrated by Wong et al. [37], who calculated that the use of $2,000 \mu \mathrm{g} \cdot \mathrm{day}^{-1}$ of budesonide or equivalent for $7 \mathrm{yrs}$ results in a reduction of bone mineral density in the lumbar spine of at least $1 \mathrm{SD}$. In postmenopausal females, an effect of this magnitude is associated with a two-fold increase in fracture risk. As a result, patients currently treated with high doses of inhaled corticosteroids may well enter later life with reduced bone mineral density, as well as a degree of adrenal insufficiency. It is, therefore, important to consider the therapeutic index of inhaled corticosteroids, incorporating both the dose-response relationship for efficacy and systemic effects.

\section{Comparison with guidelines and clinical practice}

It is of concern to contrast the present findings with the therapeutic dose range recommended in national and international guidelines and formularies. For example, the recent British Guideline on the Management of Asthma recommends the use of inhaled corticosteroid with dose increments on the basis of clinical need, with provision for the dose of budesonide to be increased up to $2,000 \mu \mathrm{g} \cdot \mathrm{day}^{-1}$ to obtain adequate control if this is not achieved at lower doses [2]. Likewise, the British National Formulary gives a dose range for budesonide of $200-2,000 \mu \mathrm{g} \cdot \mathrm{day}^{-1}$ for adults [4]. Reducing the dose to within the therapeutic dose range would not only result in major financial savings, but also improve the risk-to-benefit ratio.

\section{Therapeutic implications}

One of the major therapeutic implications of these findings is at what dose of budesonide should a long-acting $\beta$-agonist
(LABA) be added if the patient has inadequately controlled asthma. The FACET study found that a four-fold increase in the dose of budesonide from 200 to $800 \mu \mathrm{g} \cdot \mathrm{day}^{-1}$ was more effective than adding formoterol to budesonide $200 \mu \mathrm{g} \cdot \mathrm{day}^{-1}$ for reducing severe exacerbations, which was the primary outcome variable [25]. In contrast, the addition of formoterol to low-dose budesonide resulted in a greater reduction in symptoms and improvement in lung function. In the OPTIMA study of subjects with mild asthma, the addition of formoterol to $200 \mu \mathrm{g} \cdot \mathrm{day}^{-1}$ of budesonide resulted in significantly greater efficacy for all outcome measures, including severe exacerbations, than increasing the dose of budesonide from 200 to $400 \mu \mathrm{g} \cdot \mathrm{day}^{-1}$ [26].

These studies indicate that considerable benefit can be achieved with the addition of a LABA to budesonide within the $200-800 \mu \mathrm{g} \cdot \mathrm{day}^{-1}$ dose range and suggests that such an approach is preferable to increasing the dose of budesonide to a range beyond the dose-response profile observed in the present study.

\section{Conclusions}

This study provides more evidence that inhaled corticosteroids exhibit a flat dose-response at higher doses with most of the therapeutic benefit being achieved with a dose of $\sim 400 \mu \mathrm{g} \cdot \mathrm{day}^{-1}$ budesonide or equivalent. Prescribing within the established therapeutic dose range for inhaled corticosteroids has an optimal risk-to-benefit ratio, whereas doses beyond the peak of the dose-response curve need to be prescribed with caution, as patients will be exposed to the potential adverse systemic effects of inhaled steroids with minimal further gain in terms of efficacy.

Conflicts of interest. The Medical Research Institute of New Zealand, the Wellington School of Medicine and Health Sciences and P3 Research have all received research grants from Astra Draco, GlaxoSmithKline and Novartis. R. Beasley and $\mathrm{S}$. Holt have received fees for consulting and speaking, and reimbursement for attending symposia from Astra Draco, GlaxoSmithKline and Novartis. M. Masoli has received reimbursement for attending symposia from Astra Draco and Novartis.

\section{References}

1. Holt S, Suder A, Weatherall M, Cheng S, Shirtcliffe P, Beasley R. Dose-response relation of inhaled fluticasone propionate in adolescents and adults with asthma: metaanalysis. BMJ 2001; 323: 253-256.

2. British Thoracic Society \& Scottish Intercollegiate Guidelines Network. British Guideline on the Management of Asthma. Thorax 2003; 58; Suppl. 1, i1-i94.

3. National Heart, Lung and Blood Institute, National Institutes for Health. Global strategy for asthma management and prevention: NHLBI/WHO Workshop Report. Bethseda, Maryland, National Institutes of Health, 1996.

4. British Medical Assoiation, Royal Pharmaceutical Society of Great Britain. British National Formulary. London, BMA, RPS, 2000; pp. 147 (No.40).

5. Herxheimer A. Commentary: dosage needs systematic and critical review. BMJ 2001; 323: 257.

6. Thorsson L, Edsbacker S. Lung deposition of budesonide from a pressurized metered-dose inhaler attached to a spacer. Eur Respir J 1998; 12: 1340-1345.

7. Thorsson L. Studies on the deposition, bioavailability and 
systemic activity of glucocorticoids in man (thesis). University Hospital, Lund, 1998.

8. Johnson ES, Lanes SF, Wentworth CE, Satterfield MH, Abebe BL, Dicker LA. A meta-regression analysis of the dose-response effect of aspirin on stroke. Arch Int Med 1999; 159: $1248-1253$

9. Sutton AJ, Abrams K, Jones D, Sheldon T, Son F. Methods for Meta-analysis in Medical Research. Chichester, John Wiley \& Sons Ltd, 2000.

10. D'Agostino RB, Weintraub M. Meta-analysis: a method for synthesizing research. Clin Pharmacol Ther 1995; 58: 605616.

11. Busse WW, Chervinsky P, Condemi J, et al. Budesonide delivered by turbuhaler is effective in a dose-dependent fashion when used in the treatment of adult patients with chronic asthma. J Allergy Clin Immunol 1998; 101: 457-463.

12. Kemp J, Wanderer A, Ramsdell J, et al. Rapid onset of control with budesonide turbuhaler in patients with mild to moderate asthma. Ann Allergy Asthma Immunol 1999; 82: 463-471.

13. Miyamoto $\mathrm{T}$, Takahashi $\mathrm{T}$, Nakajima $\mathrm{S}$, et al. A double blind, placebo-controlled dose-response study with budesonide turbuhaler in Japanese asthma patients. Respirology 2000; 3: 247-256.

14. Lorentzson S, Boe J, Eriksson G, Persson G. Use of inhaled corticosteroids in patients with mild asthma. Thorax 1990; 45: 733-735

15. O'Byrne P, Cuddy L, Taylor D, Birch S, Morris J, Syrotuik J. Efficacy and cost benefit of inhaled corticosteroids in patients considered to have mild asthma in primary care practice. Can Respir J 1996; 3: 169-175.

16. Pirozynski M, Kulaga Z, Karlstrom R. Pulmicort turbuhaler in mild to moderate asthma: comparison of initial high dose, constant low dose and placebo. Am J Resp Crit Care Med 1996; 153: A343.

17. Barnes N, Hallett C, Harris A. Clinical experience with fluticasone propionate in asthma: a meta-analysis of efficacy and systemic activity compared with budesonide and beclomethasone dipropionate at half the microgram dose or less. Resp Med 1998; 92: 95-104.

18. McKenzie A. Percutaneous absorption of steroids. Arch Derm 1962; 86: 91-94.

19. McKenzie A. Method for comparing percutaneous absorption of steroids. Arch Derm 1962; 86: 88-90.

20. Busse W, Brazinsky S, Jacobson, et al. Efficacy response of inhaled beclomethasone dipropionate in asthma is proportional to dose and is improved by formulation with a new propellant. J Allergy Clin Immunol 1999; 104: 215-222.

21. Reddel H, Jenkins C, Marks G, et al. Optimal asthma control starting with high doses of inhaled budesonide. Eur Respir $J$ 2000; 16: 226-235.

22. Chanez P, Karlstrom R, Godard P. High or standard initial dose of budesonide to control mild to moderate asthma. Eur Respir J 2001; 17: 856-862.
23. Tukiainen $\mathrm{H}$, Taivainen $\mathrm{A}$, Majander $\mathrm{R}$, et al. Comparison of high and low dose of the inhaled steroid budesonide as initial treatment in newly detected asthma. Res Med 2000; 94 : 678-683.

24. Rees T, Lennox B, Timney A, Houssain M, Turbitt M, Richardson P. Comparison of increasing the dose of budesonide to $800 \mu \mathrm{g} /$ day with a maintained dose of $400 \mu \mathrm{g} /$ day in mild to moderate asthmatic patients. Eur J Clin Res 1993; 4: 67-77.

25. Pauwels RA, Lofdahl C-G, Postma DS, et al. Effect of inhaled formoterol and budesonide on exacerbations of asthma (FACET). N Engl J Med 1997; 337: 1405-1411.

26. O'Byrne P, Barnes P, Rodriguez-Roisin R, et al. Low dose inhaled budesonide and formoterol in mild persistent asthma (OPTIMA). Am J Respir Crit Care Med 2001; 164: 13921397.

27. Foresi A, Cristina Morelli M, Catena E. Low dose budesonide with the addition of an increased dose during exacerbations in long term asthma control. Chest 2000; 117: 440-446.

28. Van der Molen T, Meyboom-De Jong B, Mulder H, Postma D. Starting with a higher dose of inhaled corticosteroids in primary care asthma treatment. Am J Respir Crit Care Med 1998; 158: 121-125.

29. Nana A, Youngchaiyud P, Charoenratanakul S, et al. Highdose inhaled budesonide may substitute for oral therapy after an acute asthma attack. J Asthma 1998; 35: 647-655.

30. Edmonds ML, Carmargo CR Jr, Brenner BE, Rowe BH Inhaled steroids for acute asthma following emergency department discharge. Cochrane Database Syst Rev 2000; 3 : CD002316.

31. Miyamoto $\mathrm{T}$, Takahashi $\mathrm{T}$, Nakajima $\mathrm{S}$, et al. A double blind, placebo-controlled steroid-sparing study with budesonide turbuhaler in Japanese oral steroid-dependent asthma patients. Respirology 2000; 5: 231-240.

32. Laursen L, Taudorf E, Weeke B. High dose inhaled budesonide in treatment of severe steroid-dependent asthma. Eur J Resp Dis 1986; 68: 19-28.

33. Nelson H, Berstein L, Fink J, et al. Oral glucocorticosteroidsparing effect of budesonide administered by turbuhaler. Chest 1998; 113: 1264-1271.

34. Barnes PJ, Pederson S, Busse WW. Efficacy and safety of inhaled corticosteroids. New developments. Am J Resp Crit Care Med 1998; 157: S1-S53.

35. Kamada A, Szefler S, Martin R, et al. Issues in the use of inhaled glucocorticoids. Am J Respir Crit Care Med 1996; 153: $1739-1748$.

36. Aaronson D, Kaiser H, Dockhorn R, et al. Effects of budesonide by means of the turbuhaler on the hypothalamicpituitary-adrenal axis in asthmatic subjects: a dose-response study. J Allergy Clin Immunol 1998; 101: 312-319.

37. Wong C, Walsh $\mathrm{L}$, Smith $\mathrm{C}$, et al. Inhaled corticosteroid use and bone-mineral density in patients with asthma. Lancet 2000; 355: 1399-1403. 